\title{
Fenomena Curhat Online pada @Cerminlelaki di Instagram
}

\author{
Ben Thiodanu, Wulan Purnama Sari \\ benthio.123@gmail.com,wulanp@fikom.untar.ac.id \\ Fakultas Ilmu Komunikasi Universitas Tarumanagara
}

\begin{abstract}
@ cerminlelaki is an Instagram account that contains male ventures uploaded to feeds so that people can get advice. Patriarchal culture requires men to behave masculine and women to behave feminine. In this highly developed digital age, it greatly influences the behavior of human communication, the anonymity that occurs in the digital world that provides space for men to confide in the digital world, especially Instagram. This research was conducted by interviewing the owner of the @ cerminlelaki account and the survey method of followers of @ cerminlelaki who had confide in @ cerminlelaki. The purpose of this study was to determine the phenomenon of male ventilation conducted on Instagram. The interview results show that by confiding in @ cerminlelaki people can confide in a very sensitive topic that cannot even be told because confide here can be based on anonymous so that the identity of the person doing the confession will be kept confidential by the @ cerminlelaki account holder. The mirror of the man opened a room for men to confide in. With the presence of mirror men prove that not only women who do confide, men also confide.
\end{abstract}

Keywords: digital era, instagram, patriarchal culture

\begin{abstract}
Abstrak
@ cerminlelaki adalah akun instagram yang berisi curhat laki-laki yang diunggah di feeds agar bisa mendapatkan saran dari orang. Budaya patriarki menuntut laki-laki untuk berperilaku maskulin dan perempuan untuk berperilaku feminim. Di era digital yang sangat berkembang ini sangat mempengaruhi perilaku komunikasi manusia, anonimitas yang terjadi di dunia digital yang memberikan ruang untuk laki-laki untuk melakukan curhat di dunia digital khususnya instagram. Tujuan penelitian ini adalah untuk mengetahui fenomena curhat lakilaki yang dilakukan di instagram. Penelitian ini dilakukan dengan metode mix methods dengan teknik pengumpulan data berupa wawancara dengan pemilik akun @ cerminlelaki dan metode survei terhadap followers @cerminlelaki yang telah melakukan curhat di @ cerminlelaki. Hasil wawancara menunjukkan bahwa dengan melakukan curhat di @ cerminlelaki orang bisa melakukan curhat dengan topik yang sangat sensitif yang bahkan tidak akan bisa diceritakan karena melakukan curhat disini bisa berbasis anonim sehingga identitas orang yang melakukan curhat akan dijaga kerahasiaannya oleh pemilik akun @cerminlelaki. @cerminlelaki membuka ruang untuk laki-laki melakukan curhat. Dengan hadirnya @ cerminlelaki membuktikan bahwa tidak hanya perempuan yang melakukan curhat, laki-laki juga melakukan curhat.
\end{abstract}

Kata Kunci: budaya patriarki, era digital, instagram

\section{Pendahuluan}

Manusia merupakan makhluk ciptaan Tuhan Yang Maha Esa dengan struktur yang sangat sempurna bila dibandingkan dengan makhluk ciptaan lainnya. Manusia juga diciptakan sebagai makhluk multidimensional, memiliki akal pikiran dan kemampuan berinteraksi sosial. Dikarenakan manusia adalah makhluk sosial, maka manusia pada dasarnya tidak mampu hidup sendiri di dalam dunia ini baik sendiri 
dalam konteks fisik maupun dalam konteks sosial. Manusia membutuhkan bantuan manusia lain untuk saling berkolaborasi dalam pemenuhan kebutuhan fungsi-fungsi sosial satu dengan lainnya. Karena pada dasarnya suatu fungsi-fungsi sosial satu dengan lainnya. Karena pada dasarnya suatu fungsi yang dimiliki oleh manusia satu akan sangat berguna dan bermanfaat bagi manusia lainnya (Bungin, 2017).

Komunikasi antar budaya terjadi jika komunikator dan komunikan memiliki budaya yang berbeda. Dalam keadaan tersebut, komunikasi yang terjadi akan terjadi masalah yang ada di dalam suatu situasi di mana suatu pesan diterka oleh suatu budaya dan akan diterka balik dalam budaya lain. Konsekuensinya, perbedaan penerkaan dalam suatu pesan karena perbedaan budaya dapat menyebabkan segala macam kesulitan (Ridwan, 2016)

Dalam budaya patriarki, masyarakat cenderung memberi label kepada perempuan sebagai makhluk yang lemah lembut dan tidak mandiri, begitu kuatnya sehingga bila ada seorang pria yang berperilaku seperti perempuan akan dijuluki seperti wanita. Padahal, anggapan di atas tidak selamanya benar. Penelitian yang dilakukan oleh Spender, sebagaimana dikutip oleh Linda Thomas, terhadap siswa di kelas, ternyata anak laki-laki ada juga yang berperilaku seperti anak perempuan. (Thomas dan Wareing dalam Juliano, 2015).

Sekitar dua dekade terakhir ini internet muncul sebagai media baru yang digunakan orang untuk berkomunikasi. Kemunculan media baru ini telah menggeser penggunaan media tradisional seperti media cetak dan elektronik lainnya. Pengantar pos yang sekitar 10 tahun yang lalu masih dapat dilihat berkeliling mengantarkan surat dengan sepeda kemudian berganti sepeda motor berwarna oranye terang kini hampir tidak pernah melintas lagi. Sebab pertukaran kabar kini dilakukan melalui internet misalnya dengan Whatsapp, Line, Skype atau melalui berbagai media sosial yang ada seperti Instagram, Twitter atau Facebook. (Azeharie dan Sari, 2015)

Media sosial adalah media online yang dimanfaatkan sebagai sarana pergaulan sosial secara online di internet. Di media sosial, para penggunanya dapat saling berkomunikasi, berinteraksi, berbagi, networking, dan berbagai kegiatan lainnya.

Media sosial menggunakan teknologi berbasis aplikasi dan website yang dapat mengubah suatu komunikasi ke dalam bentuk dialog interaktif dan praktis. Beberapa contoh media sosial yang banyak digunakan adalah YouTube, Facebook, Blog, Twitter, Instagram dan lain-lain. Di era digital yang semakin maju, media sosial tidak hanya digunakan sebagai media untuk berkomunikasi semata. Sekarang orang menggunakan media sosial untuk sarana curhat, baik secara publik maupun privat. Akun instagram @ cerminlelaki adalah salah satu sarana curhat secara privat melalui direct message dan akan diunggah ke feeds sehingga para pengikut akun @cerminlelaki bisa memberikan saran untuk orang yang melakukan curhat itu.

Di media sosial Instagram ada akun instagram bernama @cerminlelaki. @Cerminlelaki adalah akun yang menampung curhat berbasis online yang bersifat anonim khususnya dari laki-laki melalui direct message dan akan di share melalui feeds instagram serta diberikan solusi mengenai masalah yang dihadapinya tersebut. Biasanya akun ini menangani masalah khusus tentang percintaan dan kehidupan rumah tangga yang tergolong sensitif untuk diceritakan oleh teman ataupun keluarga.

Beberapa contoh judul yang ada di feeds akun instagram @ cerminlelaki yaitu "Diceraikan Tidak Mau Dimintai Izin Nikah Lagi Sulit" ,'Pacar Banyak Berbohong Membuat Hati Ragu Menikah", ,Lebih Nyaman Sama Teman Dekat Daripada Sama Tunangan", "Istri Tidak Mau Merapikan Rambut Kemaluan" dan masih banyak lainnya. 




Curhat yang masuk ke @ cerminlelaki sehari bisa mencapai 30. Bisa dilihat dari jumlah tersebut bagaimana pentingnya kehadiran @ cerminlelaki bagi orang yang membutuhkan curhat.

Berdasarkan pendahuluan di atas, tujuan penelitian kali ini adalah untuk mengetahui fenomena curhat online laki-laki yang dilakukan di Instagram dan alasan yang membuat orang ingin melakukan curhat online. Maka dari itu peneliti membuat penelitian berjudul “Fenomena Curhat online pada @ cerminlelaki di Instagram”.

\section{Metode Penelitian}

Penelitian ini menggunakan strategi eksploratoris sekuensial. Peneliti akan mengumpulkan dan menganalisis data kualitatif kemudian mengumpulkan data kuantitatif dan menganalisisnya pada tahap kedua yang didasarkan pada hasil dari tahap pertama. Bobot utama pada strategi ada di data kualitatif. Jadi, tahap pertama melakukan wawancara lalu menganalisis data kualitatif, yaitu mengetahui fenomena laki-laki yang melakukan curhat online, selanjutnya akan dilakukan penyebaran skala atau instrumen penelitian dan menganalisis data kuantitatif untuk mengetahui alasan yang membuat seseorang melakukan curhat online. Subjek penelitian ini adalah pemilik@cerminlelaki, objek penelitian ini adalah fenomena laki-laki yang melakukan curhat online. Populasi yang akan digunakan sebagai penelitian adalah follower instagram @ cerminlelaki yang melakukan curhat online. Sampel yang akan digunakan peneliti memiliki ketentuan yaitu followers @ cerminlelaki dan pernah melakukancurhatdi @cerminlelaki.

\section{Hasil Temuan dan Diskusi}

Pelopor pertama membuat format curhat online tersebut adalah @cermindramatis lalu diikuti @cerminlelaki. Dilihat dari peningkatan followers @ cerminlelaki dari awal Oktober 2018 menuju akhir November 2019 sebesar 264 ribu menunjukkan bahwa banyak orang membutuhkan platform curhat online ini. 
Hasil wawancara dengan mindad memperlihatkan bagaimana aktivitas curhat online di dunia digital khususnya instagram. Dapat dikatakan bahwa instagram pada jaman sekarang bisa digunakan untuk menjadi platform untuk melakukan curhat online. Curhat online di sini memiliki artian yang berbeda dengan melakukan curhat di instastory. Curhat online di sini diartikan melakukan curhat kepada seseorang (@cerminlelaki) dan bersifat anonim sehingga bisa melakukan curhat apapun dan sesensitif apa pun. Langkah - langkah dalam memproses curhat seseorang hingga masuk ke feeds adalah sebagai berikut : mengirimkan curhat ke direct message @ cerminlelaki, mindad akan menyeleksi atau memilih curhat yang pantas untuk di unggah di feeds, Jika ada curhat yang tidak diunggah ke feeds, mindad akan tetap memberikan saran langsung dengan cara membalas direct message, mindad akan mengunggah curhat dan memberikan saran di kolom caption serta followers @ cerminlelaki bisa turut serta memberikan saran dan dukungan kepada curhater.

Kemajuan teknologi memberikan hal baru yang bisa dinikmati oleh semua orang. Banyak orang ingin berbicara sesuatu atau melakukan sesuatu tanpa diketahui identitasnya. Bisa menjadi anonim di dunia maya adalah salah satu hal baru yang sangat berguna bagi banyak orang. Dengan demikian orang bisa melakukan apapun secara bebas di dunia maya. Budaya patriarki menuntut laki-laki menjadi maskulin, sehingga akan terlihat aneh jika laki-laki tidak berperilaku maskulin. Curhat adalah kegiatan yang identik dengan feminim atau hal yang biasa dilakukan oleh perempuan. Dengan hadirnya @cerminlelaki yang bisa menyimpan identitas curhater sebaik mungkin, budaya patriarki yang menyebutkan bahwa laki-laki harus berperilaku maskulin bisa diatasi dengan anonimitas yang terjadi di dunia digital khususnya media sosial.

Perbedaan followers @cerminlelaki dan @cermindramatis yang mencapai sekitar 70 ribu orang membuktikan bahwa laki-laki butuh tempat untuk curhat karena bersifat anonim, berbeda dengan perempuan yang sudah lumrah melakukan curhat, mereka bisa melakukan curhat dimana saja tanpa takut dicela oleh masyarakat maya.

Gambar 2. Perbandingan Followers@cerminlelakidan@cermindramatis
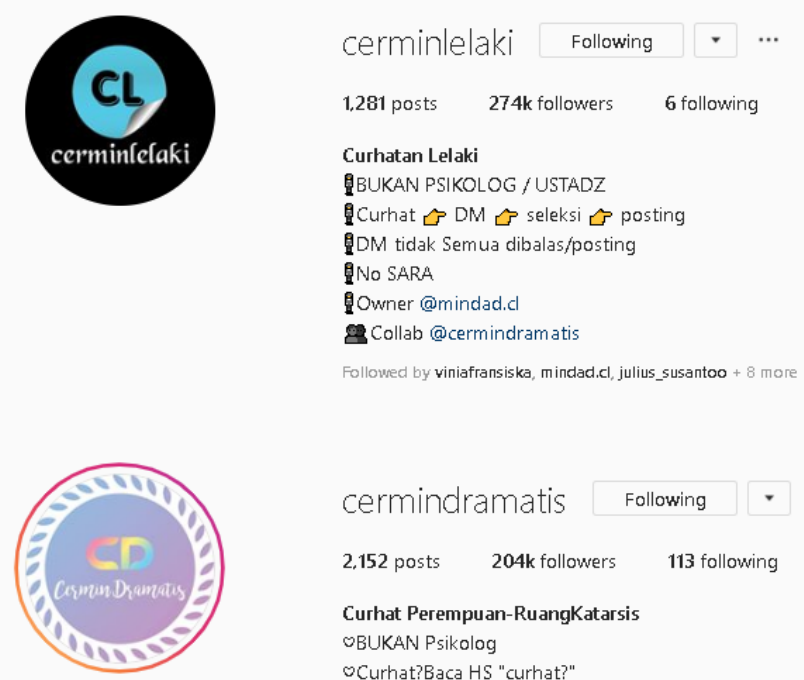
Budaya patriarki menuntut laki-laki menjadi maskulin, sehingga akan terlihat aneh jika laki-laki tidak berperilaku maskulin. Curhat adalah kegiatan yang identik dengan feminim atau hal yang biasa dilakukan oleh perempuan. Dengan hadirnya @ cerminlelaki yang bisa menyimpan identitas curhater sebaik mungkin, budaya patriarki yang menyebutkan bahwa laki-laki harus berperilaku maskulin bisa diatasi dengan anonimitas yang terjadi di dunia digital khususnya media sosial.

Dengan hadirnya @cerminlelaki, laki-laki bisa dengan bebasnya melakukan curhat tanpa memikirkan budaya patriarki yang menyatakan bahwa laki-laki harus berperilaku maskulin.

Tabel 1. Usia Responden

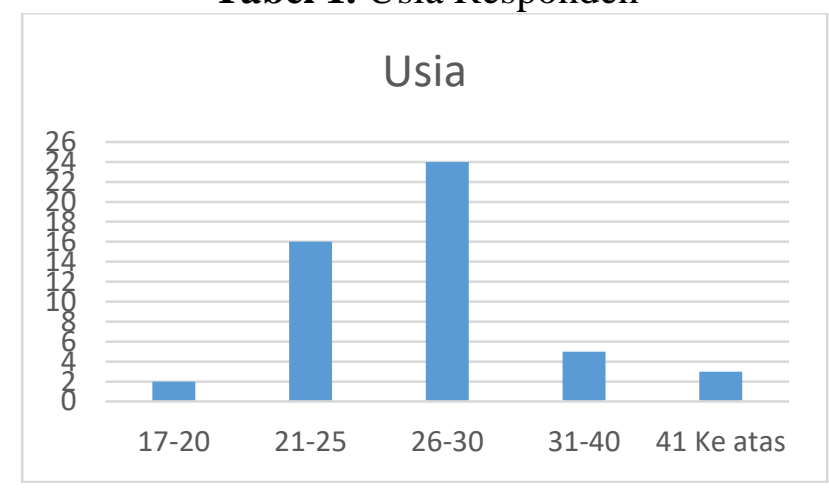

Menurut Psikolog Tara Adhisti de Thouars, ada banyak target yang ingin dikejar dewasa muda yaitu : pencapaian kinerja yang sukses, juga memilih pendamping hidup. Bisa diambil kesimpulan bahwa orang di umur 21 sampai 30 rentan terhadap masalah dan mengalami stres (Harsono, 2018).

Tabel 2. Status Hubungan Responden

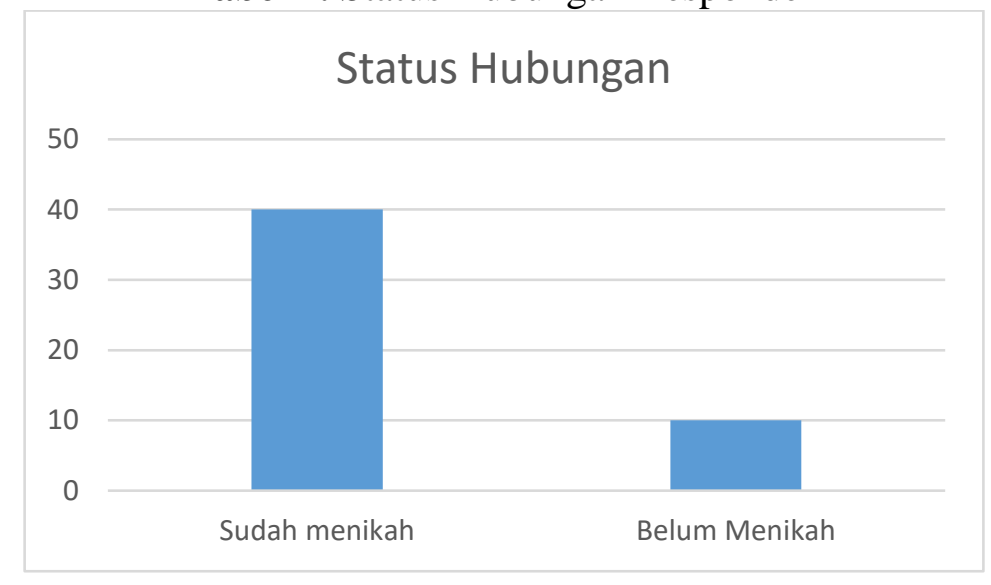

Berdasarkan hasil dari tabel di atas menunjukkan sesuai dengan apa yang diberitahu oleh mindad bahwa topik curhat yang biasa diterima mayoritas adalah masalah yang dihadapi oleh orang yang sudah menikah. Hasil ini diperkuat juga menurut survey Indonesia Milenial Report 2019 bahwa usia ideal menikah adalah $66,3 \%$ usia 21 sampai 25, dan $28,1 \%$ usia 26 sampai 30 tahun. Hasil survei Badan Pusat Statistik (2013) menunjukkan bahwa mereka yang tidak menikah lebih berbahagia daripada yang menikah. 
kehadiran curhat online yang bisa memberikan cara baru untuk laki-laki bisa melakukan curhat karena bersifat anonim. Budaya patriarki yang menyatakan bahwa laki-laki harus berperilaku maskulin ternyata tidak benar, perbedaan pengikut @cermindramatis dan @cerminlelaki membuktikan bahwa laki-laki juga membutuhkan curhat.

\section{Ucapan Terima Kasih}

Peneliti ingin menyampaikan ucapan terima kasih kepada Mindad selaku admin@cerminlelaki, responden yang bersedia mengisi survei karena telah membantu dalam menyelesaikan jurnal ini.

\section{Daftar Pustaka}

Aang, Ridwan. (2016). Komunikasi Antarbudaya:Mengubah Persepsi dan Sikap Dalam Meningkatkan Kreativitas Manusia. Bandung: Pusaka Setia Bandung.

Azeharie, S., \& Sari, W. P. (2015). Penyingkapan Diri Ibas Yudhoyono Dalam Instagram Dan Reaksi. Jurnal Komunikasi, 112. November 10, 2019. Terarsip di: https://journal.untar.ac.id/index.php/komunikasi/article/view/11/32

Bungin, B. (2017). Sosiologi Komunikasi : Teori, Paradigma, dan Diskursus Teknologi Komunikasi di Masyarakat Edisi Pertama. Jakarta: KENCANA.

Harsono, F. H. (2018, 3 14). Stres Rentan Dialami Orang dengan Usia Ini. November 1, 2019. Retrieved from 6: https://www.liputan6.com/health/read/3370200/stres-rentan-dialami-orangdengan-usia-ini

Juliano, P. Sangra. (2015). Komunikasi dan Gender : Perbandingan Gaya Komunikasi Dalam Budaya Maskulin dan Feminim .Jurnal Ilmu Politik dan Komunikasi. https://repository.unikom.ac.id/30705/1/sangra-juliano-p.pdf

Kartsen, K. (2017, 2 15). Benarkah Menikah Pilihan Hidup? Menilik Fenomena Lajang di Indonesia. November 1, 2019. Retrieved from Buletin KPIN: https://buletin.k-pin.org/index.php/arsip-artikel/154-benarkah-menikahpilihan-hidup-menilik-fenomena-lajang-di-indonesia

Mindad. (2019, 11 20). Curhat online di @ cerminlelaki. (Ben, Interviewer)

O, D. S., Peplau, L. A., \& E, S. T. (2009). Social psychology. Jakarta: Kencana.

West, R., \& Turner, L. H. (2008). Pengantar Teori Komunikasi, Edisi 3. Jakarta: Salemba Humanika. 